\title{
G-Cloud: New Paradigm Shift for Online Public Services
}

\author{
Arvind Bhisikar \\ Sr. Consultant, PwC \\ Add- C-290, Kidwai Nagar (E), New Delhi-110023
}

\begin{abstract}
G-Cloud in public service domain is a pay-per-use model for enabling convenient, on-demand network access to a shared pool of configurable and reliable computing resources that can be rapidly provisioned and released with minimal consumer management effort or service provider interaction. Government can use the power of G-Cloud to offer some urgently required public services within short time. In future, online public services providers can use all the models of G-Cloud (Cloud Computing in Government domain) to offer more complex service like ecommerce, e-procurement, real time processing, online transaction, online consolidation and integration of nation as well as world wide database etc. G-Cloud can be considered as a new paradigm shift for Online Public Services.
\end{abstract}

\section{General Terms}

G-Cloud, Public Service, e-Government, Online, Cloud Computing.

\section{Keywords}

Cloud, ICT, Cloud computing, e-Governance, Public Service, IaaS, SaaS, PaaS, Data Centers, Online System, IT, Green Computing, Online Public Service, G2C, G2E, G2B, G2C, on-demand, pay per use.

\section{INTRODUCTION}

In this modern era, Internet and online system is changing our total system in terms of habitual way of our working, communication, learning and interaction. These changes due to online system should reflect the way government functions towards public services in terms of the organization of the government, its relationship with its citizens, society, groups, institutions and businesses, and cooperation with other governments. Also, the increasing generalization of technology open to citizens and organizations lead to expectations and hassle on government. At the same time, governments are also like to be proactive in this domain and planning many new ways of interacting, improving public services, optimizing processes, procedures and revitalizing democracy by spending amount on Information Technology (IT).

With the use of Online Public Services, governments across the world aim to deliver more interactive services to citizens and businesses through e-Governance. Towards all the potential benefits of e-Governance, G-Cloud (Cloud Computing in Government domain) may lead to significant cost savings. GCloud entails use over the Internet of computing hardware, networking and software infrastructure as well as applications that are remotely hosted. In this paper, I describe how this newly emerged paradigm of G-Cloud can be helpful for Online Public Services.

\subsection{G-Cloud (Cloud Computing in Government domain)}

Cloud computing encompasses a whole array of services that can be hosted in a variety of manners, depending on the nature of the service involved and the data/security needs of the contracting organization. G-Cloud is fast creating a revolution in the way IT is used and procured by organizations and by individuals. According to the IEEE Computer Society, cloud computing is a paradigm in which information is permanently stored in servers on the Internet and cached temporarily on clients that include desktops, entertainment centers, table computers, notebooks, wall computers, handhelds etc. G-Cloud is the collection of scalable, virtualized resources, which is capable of hosting applications and providing services required by the users.

\subsection{Public Services}

Public services means services provided by government to its citizens, either directly or through the public sector or by financing private provision of services. E-governance is a network of organizations that includes government; non-profit and privatesector entities [1]. It is a process of reform and has no distinct boundaries. It delivers services to external and internal clients for the benefit of both government and the clients. These public services differ according to users' needs and ICT capacity, and this diversity has given rise to the development of different applications of e-Governance [2].

\section{ICT FOR PUBLIC SERVICES}

\subsection{Components of G-Cloud for Public Services}

Public Services require applications to be secure and protect the privacy of end users. Some of potential services that can be offered by Government across the world are:

- $\quad$ Government to Government (G2G)

- $\quad$ Government to Enterprise (G2E)

- Government to Business (G2B)

- Government to Consumer (G2C)

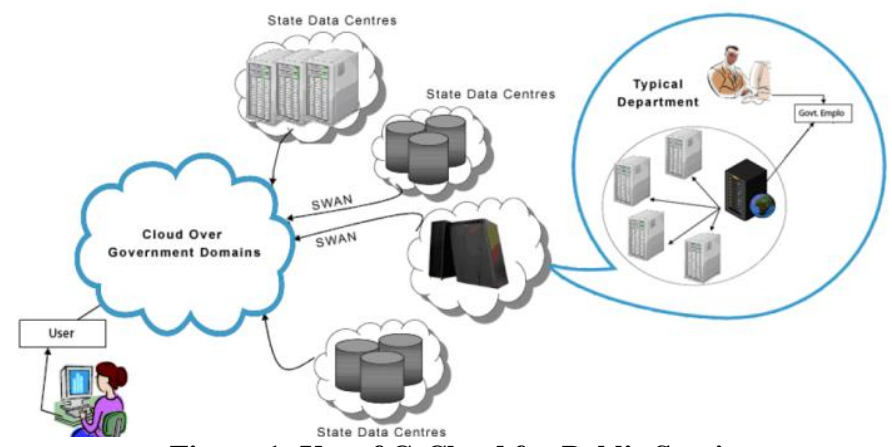

Figure 1: Use of G-Cloud for Public Services 

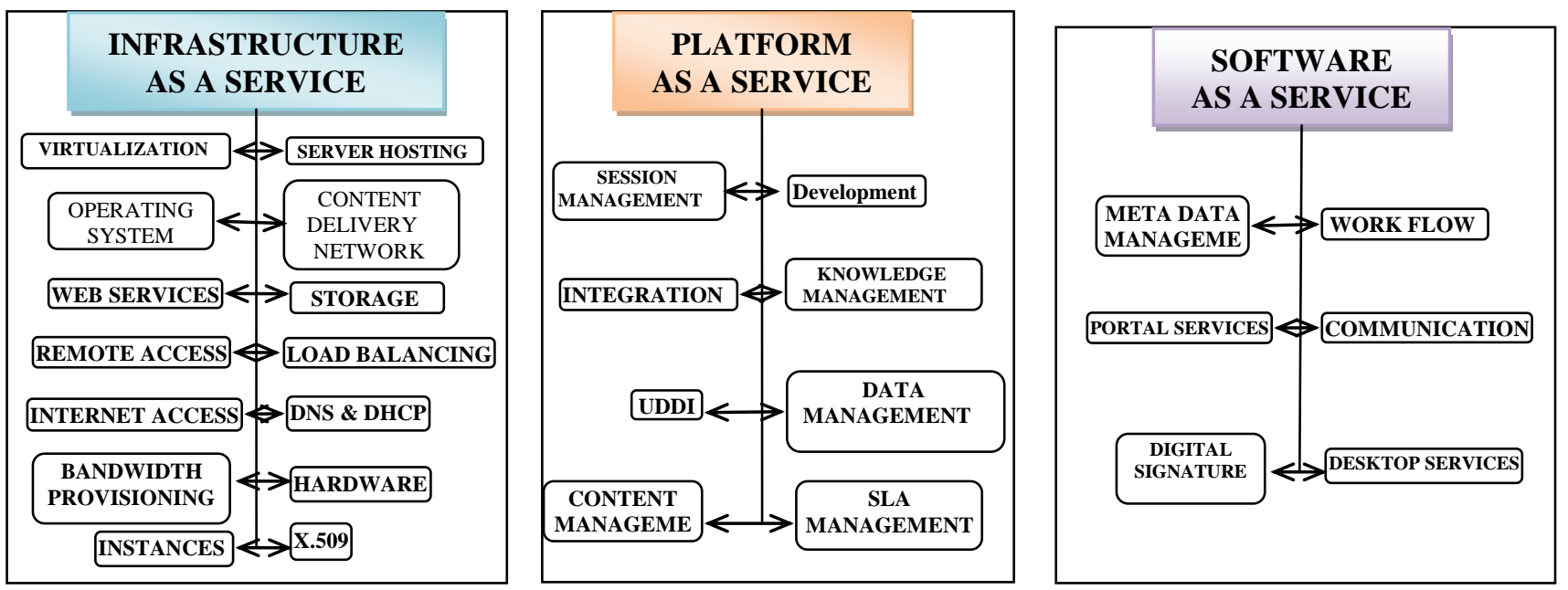

Figure 2: Components of G-Cloud (Cloud Computing in Government domain)

Information and Communication Technology (ICT) for Public Services across the world envisages to utilize potential benefits of cloud computing. It includes the need to scale and reach of IT infrastructure. But IT infrastructure has been a limiting factor for governments. The governments' ability to deploy more applications is limited by its capacity to create more datacenters. G-Cloud help governments to ensure that IT needs of concerned department are disbursed in the form of computing capacity not in the form of budgets.

G-Cloud enables green IT, which revolves capital expenditure (Cap-Ex) into operational expenditure (Op-Ex), endow with service billing (pay for use), that ensures responsive delivery of services and offers higher level service quality as well as timely on-demand services to users.

\subsection{G-Cloud: Computing as a Service}

It is a style of computing where massively scalable IT-enabled capabilities are provided "as a service" over the Internet to multiple users. Grid is an enabling technology for cloud computing.

Companies like Amazon, IBM, Google, Yahoo, Microsoft etc, provide virtualized resources on a commercial cloud, so that the users need not own the resources or invest on them but can use them transparently and dynamically as per their demand and paying capacity [9].

\subsection{IaaS, PaaS, SaaS for Public Services}

Infrastructure as a Service (IaaS) consists of delivering computer infrastructure as a service. The computer infrastructure includes servers, storage space, network equipment and system software like operating systems and database systems. The computer infrastructure is provided in the form of virtual environment. The applications are accessible from various client devices through a thin client interface such as a web browser. From the client's point of view it appears and operates exactly like standard infrastructure, while in fact it is one of many virtual environments hosted simultaneously on the same physical infrastructure resources.

Platform as a Service (PaaS) consists of delivering application development environment. It supports the full life cycle of designing, implementing, testing, and deploying web applications and services. Developers, project managers, and testers are not required to download or install any development software on their local computers. The capability provided to the consumer is to deploy onto the cloud infrastructure consumer-created or acquired applications created using programming languages and tools supported by the provider.

SaaS (Software as a Service) consists of delivering complete applications such as customer relationship management (CRM) or enterprise resource planning (ERP) over the Internet. Instead of purchasing licenses and exploiting them locally, client purchases an access to these applications. The capabilities provided to the consumers include processing, storage, networking and other fundamental computing resources, where the consumer is able to deploy and run arbitrary software, which can include operating systems and applications.

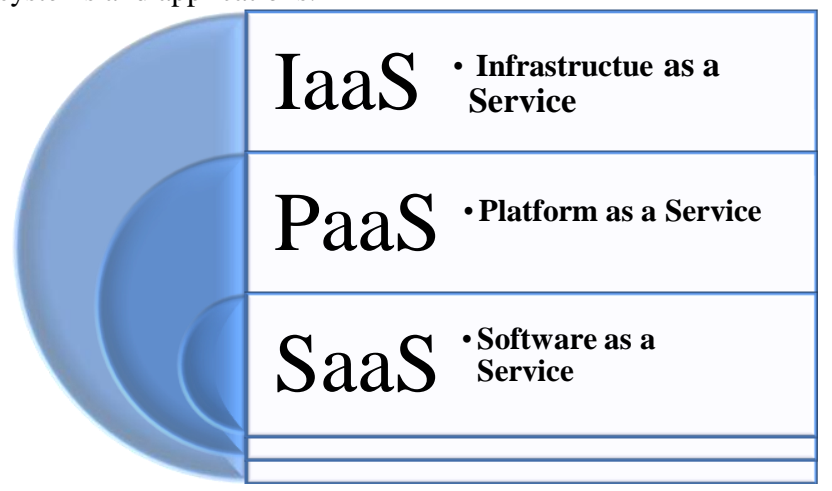

Figure 3: 3 Levels of G-cloud

\subsection{G-Cloud Deployment Model}

\subsubsection{Public Cloud}

Public cloud services are characterized as being available to clients from a third party service provider via the Internet. The term "public" does not always mean free, even though it can be free or fairly inexpensive to use. A public cloud does not mean that a user's data is publically visible. However, public cloud vendors typically provide an access control mechanism for their users. Public clouds provide an elastic, cost effective means to deploy solutions. 


\subsubsection{Private Cloud}

A private cloud offers many of the benefits of a public cloud computing environment, such as being elastic and service based. The difference between a private cloud and a public cloud is that in a private cloud-based service, data and processes are managed within the organization without the restrictions of network bandwidth, security exposures and legal requirements that public cloud services might entail. In addition, in private cloud services user access and networks used are restricted and designated. So, they offer the provider and the user greater control of the cloud infrastructure.

\subsubsection{Community Cloud}

A community cloud is controlled and used by a group of organizations that have shared interests, such as specific security requirements or a common mission. The members of the community share access to the data and applications in the cloud.

\subsubsection{Hybrid Cloud}

A hybrid cloud is a combination of a public and private cloud that interoperates. In this model, users typically outsource non-business critical information to the public cloud, while keep businesscritical services and data in their control.

\section{PARADIGM SHIFT FOR PUBLIC SERVICES}

For individuals, G-Cloud means accessing web-based email, photo sharing and productivity software, most of it for free [3]. For organizations, G-Cloud provides the ability to contract for computing services on-demand, rather than having to invest in them to host all the necessary hardware, software and support personnel necessary to provide a given level of services. For governments, the value proposition of the G-Cloud is especially appealing, given both changing demands for IT and challenging economic conditions. In fact, G-Cloud has emerged as a transformational paradigm for Public Services [4].

e-Governance is a process of reform and delivers services to external and internal users as well as stake holders for the benefit of both government and the users. Public Services requirements may be driven by economic, political, technical and cultural reasons. There are a great number of government services that can be offered online to end users in a Public Services model. The Online Public Services model adopted and implemented by many governments across the world. However the potential benefit of these online public services is limited to the regular users of the internet. In many countries citizen still like to be online system instead of inline.

\subsection{Changing Scenario}

Public Services with G-Cloud offer integration management, automated problem resolution, end-to-end security, and budgeting based on actual usage of data. At a global level, cloud architectures can benefit government to reduce duplicate efforts and increase effective utilization of resources. This in turn helps the government going green, reducing pollution and effective waste management. Small and medium enterprises are already reaping the benefits of G-Cloud by using the massive scalability and ready availability features of pay-as-you-use service model [5].

Since government requires a massive infrastructure, it is important for government to use G-Cloud on long term basis. A unified e- government infrastructure, based on Service Oriented Architecture (SOA) is required. It would pave the way for inter-agency information sharing, streamline workflow and would enable the delivery of seamless services to the public [8]. Cloud architectures allow rapid deployment of turn key test environments with little or no customization.

\subsection{Future Technology}

Today's ICT infrastructure is much more complex. So, future technology focusing on Public Services should include distributed computing system (High level Clusters \& Grids: Peta-Flop Computing); Internet \& connectivity (Optical Fiber Cables: einfrastructures: Terabit Networking); virtualization (Distributed File System: Exabyte Storage); heterogeneity and multidisciplinary information; and support advance Software (Open Source Software and Open Standards)[6, 10].

\subsection{Green Computing Initiative}

Green computing or green IT, refers to environmentally sustainable computing or IT. It has been seen that almost half of recurring expenses on data centers come from power bills So, data centers are being redesigned to enable green business processes. For this purpose, energy efficient technologies like blade servers, thin client, LCD's etc are used. Measures like consolidation and virtualization are used to achieve optimal utilization of IT infrastructure. Green computing initiatives and energy efficient technologies reduce emissions and increase cooling efficiency [7].

\section{PERFORMANCE, TRENDS AND PLAYERS}

To examine performance trend and players in e-Government, we may take a reference of "2011 Waseda University World eGovernment ranking“. This ranking comprises of monitoring and comparison of development of e-Government worldwide[11].

Table 1 Ranking of top 10 countries in e-government domain

\begin{tabular}{|l|l|l|l|l|l|}
\hline \multicolumn{2}{|l|}{$\mathbf{2 0 0 9}$} & \multicolumn{2}{|c|}{$\mathbf{2 0 1 0}$} & \multicolumn{2}{|c|}{ 2011 } \\
\hline 1 & Singapore & 1 & Singapore & $\mathbf{1}$ & Singapore \\
\hline 2 & USA & 2 & UK & $\mathbf{2}$ & USA \\
\hline 3 & Sweden & 3 & USA & $\mathbf{3}$ & Sweden \\
\hline 4 & UK & 4 & Canada & $\mathbf{4}$ & Korea \\
\hline 5 & Japan & 5 & Australia & $\mathbf{5}$ & Finland \\
\hline 5 & Korea & 6 & Japan & $\mathbf{6}$ & Japan \\
\hline 7 & Canada & 7 & Korea & $\mathbf{7}$ & Canada \\
\hline 8 & Taiwan & 8 & Germany & $\mathbf{8}$ & Estonia \\
\hline 9 & Finland & 9 & Sweden & $\mathbf{9}$ & Belgium \\
\hline 10 & Germany & 10 & Taiwan & $\mathbf{1 0}$ & UK \\
\hline
\end{tabular}

In this ranking, Singapore remains a top for the third year in a row, after that USA. Earlier USA which had been placed first during 2005-2008 and second in 2010.

\subsection{Main Trends of e-Government by Indicators}

Altogether, there are seven main indicators used to carry out the survey. These indicators are: network preparedness, required interface-functioning applications, management optimization, and national portal, CIO in government, e-Government promotion and e-participation. These seven indicators comprise 31 dimensions, which are further broken down into sub indicators. 
Table 2 Performance indicators and dimensions in E-government

\begin{tabular}{|c|c|}
\hline Indicators & Dimensions \\
\hline $\begin{array}{l}\text { 1.Network } \\
\text { Preparedness }\end{array}$ & $\begin{array}{l}\text { 1-1 Internet Users } \\
\text { 1-2 Broadband Subscribers } \\
\text { 1-3 Mobile Cellular Subscribers } \\
\text { 1-4 PC Users }\end{array}$ \\
\hline $\begin{array}{l}\text { 2. Management } \\
\text { Optimization }\end{array}$ & $\begin{array}{l}\text { 2-1 Optimization Awareness } \\
\text { 2-2 Integrated Enterprise Architecture } \\
\text { 2-3 Administrative and Budgetary } \\
\text { Systems }\end{array}$ \\
\hline $\begin{array}{l}\text { 3. Required } \\
\text { Interface- } \\
\text { Functioning } \\
\text { Applications }\end{array}$ & $\begin{array}{l}\text { 3-1 Cyber Laws } \\
\text { 3-2 e-Tender systems } \\
\text { 3-3 e-Tax system } \\
\text { 3-4 e-Payment system } \\
\text { 3-5 e-Voting system } \\
\text { 3-6 Social Security Service } \\
\text { 3-7 Civil Registration } \\
\text { 3-8 Consular Services } \\
\text { 3-9 Labor Related Service } \\
\text { 3-10 e-Health system }\end{array}$ \\
\hline 4. National Portal & $\begin{array}{l}\text { 4-1 Navigation } \\
\text { 4-2 Interactivity } \\
\text { 4-3 Interface } \\
\text { 4-4 Technical }\end{array}$ \\
\hline $\begin{array}{l}\text { 5. Government } \\
\text { CIO }\end{array}$ & $\begin{array}{l}\text { 5-1 GCIO Presence } \\
\text { 5-2 GCIO Mandate } \\
\text { 5-3 CIO Organizations } \\
\text { 5-4 CIO Development Programs }\end{array}$ \\
\hline $\begin{array}{l}\text { 6. e-Government } \\
\text { Promotion }\end{array}$ & $\begin{array}{l}\text { 6-1 Legal Mechanism } \\
\text { 6-2 Enabling Mechanism } \\
\text { 6-3 Support Mechanism } \\
\text { 6-4 Assessment Mechanism } \\
\end{array}$ \\
\hline 7 e-Participation & $\begin{array}{l}\text { 7-1 e-Information and Mechanisms } \\
\text { 7-2 Consultation } \\
\text { 7-3 Decision-Making }\end{array}$ \\
\hline
\end{tabular}

\subsection{Required Interface-Functioning Applications}

The availability of user-friendly and secure electronic services is the ultimate goal of e-Government initiatives. The indicators measures 9 core e-services such as e-Tender system, e-Tax systems, e-Voting, e-Payment system, social security services (involving payment of pensions, social benefits and insurance), civil registration services (securing birth, marriage certificates). In addition to the evaluation criteria mentioned above, the ranking is capturing the presence of cyber laws (cyber security and ecommerce laws) and security system features to protect all transactions/activities across the Internet and among offices and instrumentalities. The most recent trends show a number of governments in developing countries shifted to user-oriented strategies and maintained one-stop-service portals with plans to gradually expand and enhance their service delivery.

Open source in G-Cloud might be a significant prospective across the Public Services segment with the following benefits:
- Licenses permit and encourage redistribution that leads to Research and Development (R\&D)

- Architecture enabled programs can be used as components where-ever possible

- Open-standards, interoperability, flexibility

- Multi-lingual support

- Lowered barriers to adoption

- Data mobility

\subsection{International Players in G-Cloud for Public Services across the world}

Some well known players in this domain include Akamai; Amazon; Areti Internet; Enki; Fortress ITX; Joyent Layered Technologies; Rackspace; Salesforce.com; Terremark; XCalibre etc. All these players have innovative and reliable products and services required for e-Governance. However the market leaders in this field may include:

- Commercial Cloud: Amazon EC-2

- $\quad$ Scientific Cloud: Nimbus (University of Chicago)

- Google's App Engine

- Windows Azure

- $\quad$ Gogrid (www.gogrid.com)

- $\quad$ IBM Cloud Computing Initiative

- Open Source technologies: Globus VWS (Globus compatible), Eucalyptus (Interface similar to EC2), OpenNEbula

\section{BENEFITS OF G-CLOUD FOR PUBLIC SERVICES}

G-Cloud provides unlimited infrastructure to store and execute customer data and programs. The customers do not need to own the infrastructure as it can be rented. The potential benefits of GCloud include minimum capital expenditure; location and device independence; utilization and efficiency improvement; very high scalability; elimination of high computing power capital expenditures; and dramatically reduced ICT administrative burden as government can hire the infrastructure from clouds. The benefits of G-Cloud in Public Services are given below:

Increased flexibility: On-demand computing helps to run applications as per need. If government wants to use ERP applications with its own procedures, business solutions for ecommerce based applications such as e-procurement can be shared easily. Large group of service providers will be available due to increased flexibility.

Access anywhere: Unlike to offer government services from a single computer or network, different computers in shared network environment or portable devices (like laptops, notepads, mobile phones etc) can be used to run applications and documents everywhere.

Elastic scalability and pay-as-you-go: Only the critical infrastructure and services can be developed. Rest can be subtracted and added as per needs.

Easy to implement: No need to purchase hardware, software licenses or implementation services. Work can be started within a short time. 
Service quality: Reliable services, large storage and computing capacity. The user can get $24 * 7$ services.

Delegate non-critical applications: Non-critical applications can be outsourced to service providers and organization can focus on business-critical applications.

Availability of software updates: As software updates are automatic, organizations can get latest software without paying new purchase cost to vendor.

Sharing documents and group collaboration: Accessibility of applications and documents from anywhere in the world can help in sharing documents and facilitating group collaboration.

Data Recovery: Natural disasters like floods, earthquakes, wars and internal disturbances could cause the e- Governance applications not only loose data, but also make services unavailable. So, multiple installations in geographically separated locations with complete backup and recovery solutions are required. Applications and data should be available on a short notice to switch from one data center to center. Cloud virtualization technologies allow backups and restoring. It offers seamless application migration as compared to traditional data centers.

Distributed Data Centers: ICT based Public Services model have many risk; like attack of viruses, hackers, fire and terrorists. Some disasters possess mass destructibility and even intentioned activities after disasters. Distributed data centers provide fault tolerance against such disasters. These centers facilitate robust communication support, self-supervision capability and real visible platform.

\section{ISSUES AND CHALLENGES}

Elasticity is a great advantage of G-Cloud. Due to it, applications can be added almost at a moment's notice. Companies can buy the requisite amount of storage, computing power, security and other IT functions that they need from specialists in data-center computing. They can get sophisticated data center services on demand, and can pay for them. The service levels can be set with the vendor, along with the capabilities that can be added or subtracted at will.

The metered cost, pay-as-you-go approach appeals to small- and medium-sized enterprises as little or no capital investment and maintenance cost is needed. IT is remotely managed and maintained, typically for a monthly fee, and the company can let go of plumbing concerns. Since the vendor has many customers, it can lower the per-unit cost to each customer. Larger companies may find it easier to manage collaborations in the cloud, rather than having to make holes in their firewalls for contract research organizations. SaaS deployments usually take less time than inhouse ones, upgrades are easier, and users are always using the most recent version of the application. There may be fewer bugs because having only one version of the software reduces complexity.

This may all sound very appealing but there are downsides. In the cloud, companies may not have the kind of control over data or the performance of applications or the ability to audit or change the processes and policies under which users must work. Different parts of an application might be at many places in the cloud.

\section{CONCLUSION}

G-Cloud provides a base for widespread provision of services to various stakeholders of e-Government. Cloud computing provides service through public and private clouds with the help of vital technology like system approach, distributed system, service oriented architecture, grid computing and virtualization. The system for online public services requires entities like software, hardware, service management, network, business policy, security, infrastructure etc. to survive as well as function effectively and properly. However, currently adopted approaches or technology is insufficient to manage all these entities [12]. Thus, the potential use and applications of G-Cloud is so huge in such a way that, new and innovative approaches as well as emerging technologies in cloud computing may plays a vital roles in the domain of online public services system. G-Cloud treats all these entities as a service can be used in public service system. G-Cloud helps and enables eGoverning services faster and cheaper thereby accelerating the adoption and use of IT for online public services. The new Cloud architectures allow rapid deployment of turnkey test environments with little or no customization. It can be stated for Government domain where simply no choice but to turn cost effective, very large scale cloud-based models for computing and online public services system.

Finally it may be concluded that all the potential benefits of e-Governance, G-Cloud may lead to significant cost savings, efficiency and quick adoptable with minimum customization. G-Cloud is more relevant in online public services as a pay-per-use model for enabling convenient, on-demand network access to a shared pool of configurable and reliable computing resources that can be rapidly provisioned and released with minimal consumer management effort or service provider interaction. Much more complex and large scale service like e-commerce, e-procurement, real time processing, online transaction, online consolidation and integration of nation as well as world wide database etc. may be provide by effective use of G-Clouds. The G-Clouds entails use over the Internet of computing hardware, networking and software infrastructure as well as applications on-demand that are remotely hosted as a service and that is more useful for Online Public Services which is considered as a new paradigm shift.

\section{REFERENCES}

[1] Garson, D.G., Public Information Technology and EGovernance. Sudbury, MA: Jones and Bartlett Publishers, 2006.

[2] Armbrust, $M$ et al., "Above the Clouds: A Berkeley View of Cloud Computing, Technical Report” No.UCB/EECS-2009

[3] Anderson, Free: The future of a radical price. New York: Hyperion, April 2009.

[4] D.C. Wyld, Moving to the cloud: An introduction to cloud computing in government. Washington, DC: IBM Center for the Business of Government, November 2009.

[5] David C. Wyld, "The cloudy future of government IT: cloud computing and public sector around the world," International Journal of Web \& Semantic Technology, Vol. 1, Issue 1, January 2010.

[6] Grossman, R. L. The case of cloud computing, proc. of IEEE Educational Activities Department, Piscataway, NJ, USA vol. 11, Issue 2, pp. 23-37, March 2009 
[7] Heek, R., "Implementing and Managing E-Government," Vistaar Publication, 2006

[8] Janssen, M., "Cressworld Anthony Enterprise Architecture Integration in E-Government," Proc. of 38th Hawaii International Conference on System Sciences, 2005.

[9] L. Ulanoff, “Google's cloud: 8 key questions,” PC Magazine, February, 2009.

[10] Maria, A. F., Fenu, G., and Surcis, S., "An Approach to Cloud Computing Network," Proceedings of the 3rd International
Conference on Theory and Practice of Electronic Governance, Bogota, Colombia, vol. 322, pp. 409- 410, 2009.

[11] The 2011 Waseda University World e-Government Ranking, http://www.cicc.or.jp/english/news/e-GovRanking2011e.PDF

[12] Youseff, L., Butrico, M., and DaSilva, D., "Towards a Unified Ontology of Cloud Computing," Proc. of Grid Computing Environments Workshop 2008. 